\title{
Season Primes the Brain in an Arctic Hibernator to Facilitate Entrance into Torpor Mediated by Adenosine $A_{1}$ Receptors
}

\author{
Tulasi R. Jinka, ${ }^{1,2,3}$ Øivind Tøien, ${ }^{1}$ and Kelly L. Drew ${ }^{1,2,3}$ \\ ${ }^{1}$ Institute of Arctic Biology, ${ }^{2}$ Department of Chemistry and Biochemistry, and ${ }^{3}$ Alaska Basic Neuroscience Program, University of Alaska Fairbanks, \\ Fairbanks, Alaska 99775-7000
}

\begin{abstract}
Torpor in hibernating mammals defines the nadir in mammalian metabolic demand and body temperature that accommodates seasonal periods of reduced energy availability. The mechanism of metabolic suppression during torpor onset is unknown, although the CNS is a key regulator of torpor. Seasonal hibernators, such as the arctic ground squirrel (AGS), display torpor only during the winter, hibernation season. The seasonal character of hibernation thus provides a clue to its regulation. In the present study, we delivered adenosine receptor agonists and antagonists into the lateral ventricle of AGSs at different times of the year while monitoring the rate of $\mathrm{O}_{2}$ consumption and core body temperature as indicators of torpor. The $A_{1}$ antagonist cyclopentyltheophylline reversed spontaneous entrance into torpor. The adenosine $A_{1}$ receptor agonist $\mathrm{N}^{6}$-cyclohexyladenosine (CHA) induced torpor in six of six AGSs tested during the mid-hibernation season, two of six AGSs tested early in the hibernation season, and none of the six AGSs tested during the summer, off-season. CHAinduced torpor within the hibernation season was specific to $A_{1} A R$ activation; the $A_{3} A R$ agonist 2-Cl-IB MECA failed to induce torpor, and the $\mathrm{A}_{2 \mathrm{a}} \mathrm{R}$ antagonist MSX-3 failed to reverse spontaneous onset of torpor. CHA-induced torpor was similar to spontaneous entrance into torpor. These results show that metabolic suppression during torpor onset is regulated within the CNS via $A_{1} A R$ activation and requires a seasonal switch in the sensitivity of purinergic signaling.
\end{abstract}

\section{Introduction}

Hibernation is essential for survival during seasonal deficiencies in food supply in several diverse lineages of mammals (Carey et al., 2003; Dausmann et al., 2004; Heldmaier et al., 2004). Survival is achieved by severe metabolic suppression, termed torpor, where rates of $\mathrm{O}_{2}$ consumption fall to as low as $1 \%$ of resting metabolic rate and core body temperature $\left(T_{\mathrm{b}}\right)$ falls to as low as $-3^{\circ} \mathrm{C}$ (Barnes, 1989; Geiser, 2004; Heldmaier et al., 2004). Torpor in hibernating mammals thus defines the nadir of mammalian metabolism and $T_{\mathrm{b}}$, but mechanisms regulating initiation of torpor have been poorly understood (Heldmaier et al., 2004; Drew et al., 2007). Transition into the torpid state has been postulated to include three processes: (1) altered CNS control of thermoregulatory processes (Heller et al., 1977) and an extension of sleep (Walker et al., 1977, 1980), (2) active inhibition of metabolism such as inhibition of mitochondrial oxidative

Received March 9, 2011; revised May 5, 2011; accepted June 6, 2011.

Author contributions: T.R.J. and K.L.D. designed research; T.R.J. performed research; Ø.T. contributed unpublished reagents/analytic tools; T.R.J., Ø.T., and K.L.D. analyzed data; T.R.J., Ø.T., and K.L.D. wrote the paper.

This work was supported by U.S. Army Research Office Grant W911NF-05-1-0280, U.S. Army Medical Research and Materiel Command Grant 05178001, National Institute of Neurological Disorders and Stroke Grants NS041069-06 and R15NS070779, and Alaska Experimental Program to Stimulate Competitive Research. The content of this report is solely the responsibility of the authors and does not necessarily represent the official views of the National Institute of Neurological Disorders and Stroke or the National Institutes of Health. We thank B. Warlick, C. L. Buck, and B. M. Barnes for critical discussions or reading of the manuscript, B. Rasley for technical assistance, and J. Moore, L. Bogren, Z. Carlson, and J. Olson for support. We also thank J. Vonnahme, H. Crispell, L. Norris, C. Pylant, and V. Combs for assisting with surgeries, and J. Blake, C. Willetto, and C. Terzi for veterinary support.

The authors declare no competing financial interests.

Correspondence should be addressed to Kelly L. Drew at the above address. E-mail: kdrew@alaska.edu. DOI:10.1523/JNEUROSCI.1240-11.2011

Copyright $\odot 2011$ the authors $\quad 0270-6474 / 11 / 3110752-07 \$ 15.00 / 0$ phosphorylation (Muleme et al., 2006), and (3) temperaturedependent effects on metabolic rate, or " $\mathrm{Q}_{10}$ effects" (Geiser, 2004). For larger mammals, the debate has centered more extensively on CNS control versus active suppression of metabolism via modulation of biochemical processes within metabolically active tissues.

In seasonal (obligate) hibernators, such as the arctic ground squirrel (AGS; Urocitellus parryii), torpor depends on a circannual cycle. The circannual cycle persists under constant photoperiods with food provided ad libitum (Heller and Poulson, 1970; Pengelley et al., 1976; Lee and Zucker, 1991). The seasonal character of hibernation thus provides a clue to its regulation. Once torpor ensues animals rewarm spontaneously every 2-3 weeks for brief $(12-24 \mathrm{~h})$ periods of normal body temperature (termed euthermy). This cycle continues until torpor ceases to occur in the spring. A two-switch model suggests that one physiological switch initiates the onset of the hibernation season and another switch initiates the onset of torpor (Serkova et al., 2007). The role of the CNS or the nature of the signaling events involved in either of these two switches have been unknown. Central purinergic signaling via $A_{1}$ adenosine receptors ( $A_{1} A R s$ ) mediates sleep drive (Benington et al., 1995; Porkka-Heiskanen and Kalinchuk, 2011) and decreases body temperature (Miller and Hsu, 1992; Barros et al., 2006), and more recently, endogenous adenosine within the CNS has been found to decrease body temperature at presumed torpor onset in hamsters (Mesocricetus auratus) (Shiomi and Tamura, 2000; Tamura et al., 2005). Here we used intracerebroventricular drug administration to test the hypothesis that a seasonal change in purinergic signaling within the CNS is necessary for the onset of spontaneous torpor in the AGS, a 


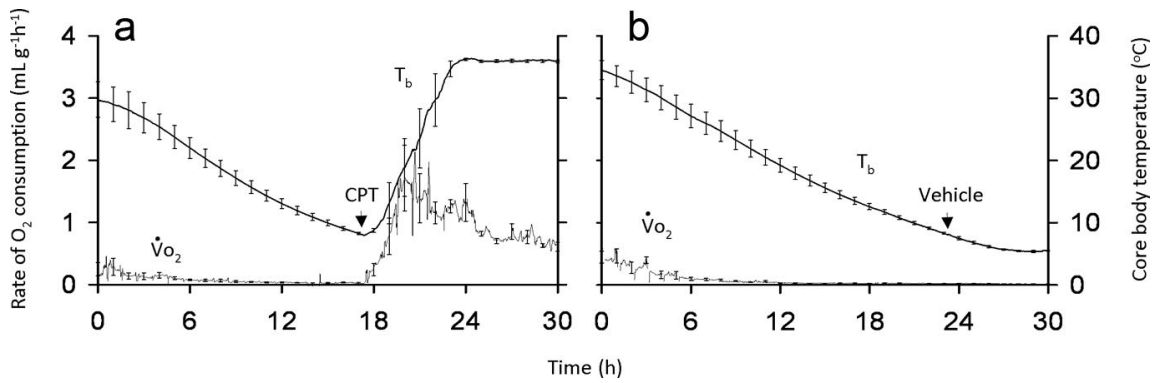

Figure 1. Onset of torpor requires $A_{1} A R$ activation. $\boldsymbol{a}$, An increase in the rate of $0_{2}$ consumption $\left(\dot{V}_{0_{2}}\right)$ and an increase in $T_{b}$ to euthermic levels occurred in all animals tested following administration of CPT ( $3 \mathrm{nmol}$, i.c.v.) during onset of spontaneous torpor. This indicates that $A_{1} A R$ activation is necessary for torpor onset. $\boldsymbol{b}$, Vehicle had no effect in any of the animals tested. Results are shown as means and SEM; $n=6$ AGSs.

seasonal hibernator. We show for the first time that activation of $A_{1} A R$ within the CNS is necessary and sufficient to induce torpor in AGS during the hibernation season, but not during the offseason, when AGSs do not spontaneously hibernate. The CNS and purinergic signaling are therefore key regulators of torpor onset, and sensitization to the effects of endogenous adenosine serves as a seasonally regulated switch that facilitates $A_{1} A R-$ mediated torpor.

\section{Materials and Methods}

Animals. Procedures were approved by the University of Alaska Fairbanks Institutional Animal Care and Use Committee and Department of Defense Animal Care and Use Review Office. AGSs were captured near $66^{\circ} 38^{\prime} \mathrm{N}, 149^{\circ} 38^{\prime} \mathrm{W}$ under permit from the Alaska Department of Fish and Game. Animals were fed rodent chow and housed at $20^{\circ} \mathrm{C}$ with natural lighting for their wild-trapped latitude until mid-August, when they were moved to environmental chambers set to $2^{\circ} \mathrm{C}$ and $4: 20 \mathrm{~h}$ light: dark (L:D). AGSs remained in these conditions until the end of the study. The hibernation season was defined by the presence of spontaneous torpor. The off-hibernation season (off-season) was defined by an absence of spontaneous torpor. Torpor was monitored daily by placing shavings on the animals' backs.

Surgery. Under sterile conditions, telemetry transmitters (model VMFH, MiniMitter, or model CTA-F40, Data Sciences International) were implanted under isoflurane anesthesia. The head was leveled in a rat stereotaxic frame (Stoelting). Copalite (Cooley \& Cooley) was applied to the skull. A target was marked at $\mathrm{AP}_{\mathrm{EBZ}}+8.5 \mathrm{~mm}, \mathrm{~L}_{\mathrm{EBZ}}+3.0 \mathrm{~mm}$, the arm was tilted $15^{\circ}$, and the cannula tip was repositioned on the target. An internal cannula extending $1.0 \mathrm{~mm}$ beyond the guide cannula was connected to a syringe primed with sterile saline. The cannula assembly was lowered $5.5 \mathrm{~mm}$ from the brain surface and retracted until CSF was withdrawn. The guide cannula was secured to anchoring screws (Stoelting) and plugged with a dummy cannula (Plastics One). Animals received enrofloxacin (Bayer Health Care) $(5 \mathrm{mg} / \mathrm{kg}$, s.c., BID for $3 \mathrm{~d}$ ), and ketoprofen (Fort Dodge Animal Health, $1 \mathrm{mg} / \mathrm{kg}$, QD, s.c., for $3 \mathrm{~d}$ total). When CTA-F40 transmitters were used, animals received buprenorphine (Hospira, $0.03 \mathrm{mg} / \mathrm{kg}$, QD, i.m., for $3 \mathrm{~d}$ ) and 2 weeks separated transmitter surgery and intracerebroventricular cannula surgery. Following surgery, animals were housed at $20^{\circ} \mathrm{C} 4: 20 \mathrm{~h} \mathrm{~L}: \mathrm{D}$ and wounds were cleaned for $10 \mathrm{~d}$ before returning to environmental chambers at $2^{\circ} \mathrm{C}$. Surgery was performed at least 1 month before drug testing.

$\mathrm{O}_{2}$ consumption and body temperature. A cylindrical Plexiglas metabolic chamber (diameter $28 \mathrm{~cm}$, height $23 \mathrm{~cm}$ ) on a rat-turn (Bioanalytical Systems) was positioned over a telemetric receiver and $T_{\mathrm{b}}$ was acquired using DataQuest software A.R.T.2.3 (Data Sciences International). Air was drawn from a gas-tight swivel at the bottom of the chamber, filtered, and passed through a mass flow controller at $3 \mathrm{~L} / \mathrm{min}$ (Model 840, 0-5 L/min, Sierra Instruments), and a subsample was passed through a multiplexing valve system and dried by a Nafion drier used in reflux mode (model PD-50T-24-PP, Perma Pure) before passing through the $\mathrm{O}_{2}$ and $\mathrm{CO}_{2}$ analyzers (Model FC-1B and CA-2A, Sable
Systems International). The automated data acquisition and analysis software (LabGraph, developed by Tøien) interpolated between calibrations. $\mathrm{O}_{2}$ consumption was corrected for respiratory volume change according to the principles of the Haldane transformation (Wagner et al., 1973; Karpovich et al., 2009). The integrity of the system was tested during and after the study period by burning $100 \%$ ethanol. Measured $\mathrm{O}_{2}$ consumption was within $4 \%$ of that calculated from the weight loss of the lamp.

For monitoring subcutaneous temperature following intraperitoneal $\mathrm{CHA}$ injections, animals were implanted with IPTT-300 transponders (Bio Medic Data Systems), subcutaneously between the scapula. $T_{\mathrm{b}}$ was monitored using a telemetry system (DAS-6000; Bio Medic Data Systems) in the home cage every 30-60 min for at least $1 \mathrm{~h}$ before drug injection and every $1 \mathrm{~h}$ after injection for $4 \mathrm{~h}$ and again $30 \mathrm{~h}$ after intraperitoneal injection of CHA. Because the IPTT transponders are not reliable below $\sim 30^{\circ} \mathrm{C}$, to confirm minimal $T_{\mathrm{b}}$ at $30 \mathrm{~h}$, rectal temperature was monitored with a thermocouple (Model H H21 Microprocessor Thermometer, Type J-K-T Thermocouple, OMEGA Engineering) in animals that were torpid after $30 \mathrm{~h}$.

Drug administration. Animals tested for drug-induced torpor were aroused on day 3 or 4 of a torpor bout and moved from the environmental chamber $\left(2^{\circ} \mathrm{C}, 4: 20 \mathrm{~L}: \mathrm{D}\right)$ to a warmer room $\left(20^{\circ} \mathrm{C}, 4: 20 \mathrm{~L}: \mathrm{D}\right)$, where they remained overnight. On the following day, they were handled as described below and placed in the metabolic chamber for baseline recordings for at least $1 \mathrm{~h}$ before drug administration. For intracerebroventricular administration of $\mathrm{CHA}$, injection cannulae primed with $\mathrm{CHA}$ or vehicle by an observer unaware of treatment were connected to a perfusion pump (Harvard Apparatus). Euthermic animals were lightly anesthetized with isoflurane as described for surgery and fit with a harness and injection cannula in a way that allowed animals to move freely within the metabolic chamber. After recovery from anesthesia, baseline $\mathrm{O}_{2}$ consumption and $T_{\mathrm{b}}$ were collected for $1 \mathrm{~h}$ before delivering the drug $(0.5$ nmol CHA/10 $\mu \mathrm{l}$, delivered over $1 \mathrm{~min})$ or vehicle (10 $\mu \mathrm{l}$, delivered over $1 \mathrm{~min}$ ). The cannula was left in place and $\mathrm{O}_{2}$ consumption and $T_{\mathrm{b}}$ were monitored for at least $24 \mathrm{~h}$ or until $T_{\mathrm{b}}$ was stable. Solutions used to dissolve the drugs (vehicle) were administered in a balanced cross-over design by an observer unaware of treatment. In this way, half of the animals received drug on the first test and vehicle on the second test and the other half received vehicle on the first test and drug on the second. Drug and vehicle tests were separated by at least 1 week. In a separate group of animals, a Y-injection cannula (Plastics One) was primed with 2-Cl-IB-MECA ( $3 \mathrm{nmol} / 10 \mu \mathrm{l})$, and the secondary line was primed with CHA $(0.5 \mathrm{nmol} / 10 \mu \mathrm{l})$. Animals were treated as above except that the injection of 2-Cl-IB MECA ( $10 \mu \mathrm{l}$, delivered over $1 \mathrm{~min})$ was followed by a second injection of CHA (3.3 $\mu \mathrm{l}$ to clear the cannula of 2-Cl-IB MECA, then $10 \mu \mathrm{l}$ of CHA at $10 \mu \mathrm{l}$, delivered over $1 \mathrm{~min}$ ).

Additional animals received pentobarbital $(20 \mathrm{mg} / \mathrm{kg}$, i.p. $)$ during the midseason or off- (nonhibernating) season and $T_{\mathrm{b}}$ and $\mathrm{O}_{2}$ consumption were monitored as described above. To ensure that the stress of intraperitoneal injections did not interfere with drug-induced torpor, a separate group of AGSs was administered CHA intraperitoneally during midseason.

For antagonist studies, torpid AGSs were habituated to handling before drug testing. During habituation, AGSs were handled daily to mimic handling necessary for the experiment until handling failed to induce arousal. At the next signs of torpor when $T_{\mathrm{b}}$ dipped to $\sim 34^{\circ} \mathrm{C}$, AGSs were fit with a harness and an injection cannula primed with antagonist (CPT, $3.0 \mathrm{nmol} / 10 \mu \mathrm{l}$ ) or vehicle by an experimenter unaware of treatment and onset of torpor proceeded without interruption. When $T_{\mathrm{b}}$ reached $10^{\circ} \mathrm{C}$, $10 \mu \mathrm{l}$ was delivered over $1 \mathrm{~min}$ and the cannula was left in place for an additional $24 \mathrm{~h}$. MSX-3 $(3.0 \mathrm{nmol} / 10 \mu \mathrm{l})$ was administered in the same way to another group of animals. The $3 \mathrm{nmol}$ dose of MSX-3 was considered to be equipotent to the $3 \mathrm{nmol}$ dose of CPT since MSX-2 has 

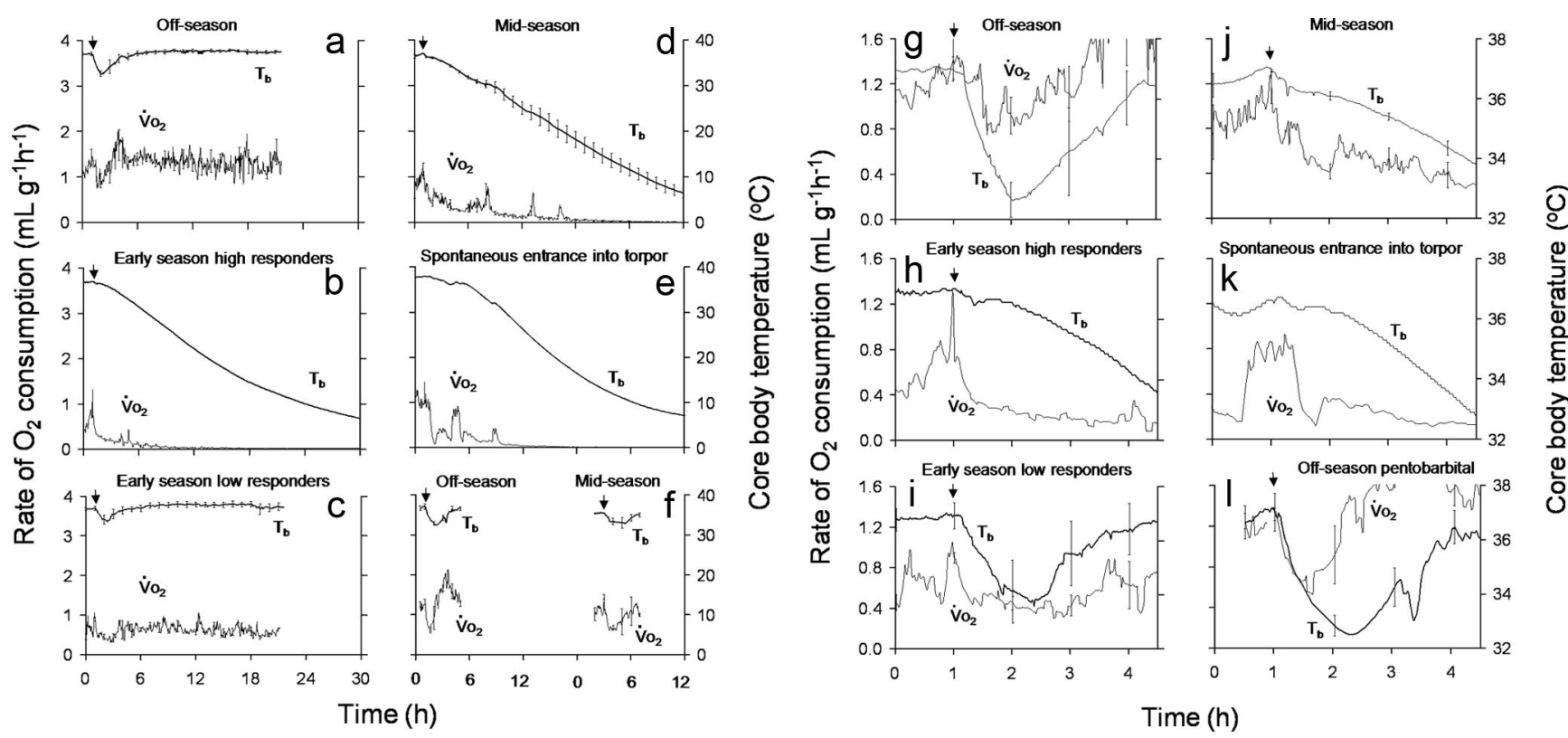

Figure 2. Sensitivity to the torpor-inducing effects of the $A_{1} A R$ agonist CHA increases as the hibernation season progresses. $\boldsymbol{a}$, CHA during the off-season, when animals were not displaying spontaneous torpor, induced a slight decrease in $\dot{V}_{0_{2}}$ and $T_{\mathrm{b}}$ in all six AGSs tested. $\boldsymbol{b}$, Early in the hibernation season after all animals showed evidence of spontaneous torpor, $\mathrm{CHA}$ induced a torpor-like response in two of six animals tested. $\boldsymbol{c}$, In the remaining four animals, the same dose of the drug did not induce torpor. $\boldsymbol{d}$, By the middle of the hibernation season (midseason), the same dose of $\boldsymbol{C H A}$ induced torpor in all six AGSs tested. $\boldsymbol{e}$, Spontaneous torpor in one AGS.f, Pentobarbital, regardless of season, induced a response similar to CHA during the off-season ( $n=3$ ). (The time scale on the $\boldsymbol{x}$-axis in $\mathbf{c}$ applies to $\boldsymbol{d}$ and $\boldsymbol{e}$ and is a continuous $30 \mathrm{~h}$.) $\boldsymbol{g} \boldsymbol{- I}$, Detail of the first $4.5 \mathrm{~h}$ of $\boldsymbol{a}-\boldsymbol{f}$ illustrates that CHA-induced torpor resembles spontaneous torpor where a rapid drop in metabolism is followed by a slow gradual decrease in $T_{\mathrm{b}}$. $\boldsymbol{g}$, During the off-season $\mathrm{CHA}$ induces a rapid drop in $T_{\mathrm{b}}$ that begins before and at the same rate as the decline in $\mathrm{O}_{2}$ consumption. $\boldsymbol{h}, \boldsymbol{j}, \boldsymbol{k}$, When $\mathrm{CHA}_{\mathrm{induces}}$ torpor $(\boldsymbol{h}, \boldsymbol{j})$ and when animals spontaneously enter torpor $(\boldsymbol{k}), T_{\mathrm{b}}$ declines more slowly than $\mathrm{O}_{2}$ consumption. $\boldsymbol{g}, \boldsymbol{i}, \boldsymbol{I}$, When CHA fails to induce torpor $(\boldsymbol{g}, \boldsymbol{i})$ and after pentobarbital $(\boldsymbol{I}), T_{\mathrm{b}}$ and $\mathbf{O}_{2}$ consumption decline at similar rates. Data shown are means \pm SEM.

similar affinity for the $\mathrm{A}_{2 \mathrm{a}} \mathrm{AR}$ as $\mathrm{CPT}$ has for the $\mathrm{A}_{1} \mathrm{AR}$. The $3 \mathrm{nmol}$ dose of 2-Cl-IB MECA was considered to be higher than an equipotent dose of $0.5 \mathrm{nmol}$ of CHA since 2-Cl-IB MECA has a slighter higher affinity for $A_{3} A R$ than CHA has for $A_{1}$ AR (Bruns et al., 1986; Klotz, 2000; Sauer et al., 2000; Solinas et al., 2005).

Drugs. $\mathrm{N}^{6}$-Cyclohexyladenosine (CHA), 8-cyclopentyltheophylline (CPT), and phosphoric acid mono-(3-\{8-[2-(3-methoxyphenyl) vinyl]-7methyl-2,6-dioxo-1-prop-2-ynyl-1,2,6,7-tetrahydropurin-3-yl\}propyl) ester disodium salt (MSX-3) hydrate were purchased from Sigma-Aldrich, and 2-chloro- $\mathrm{N}^{6}$-(3-iodobenzyl) adenosine-5' $-\mathrm{N}$-methyluronamide (2-Cl-IB MECA) was purchased from Tocris Bioscience. CHA was dissolved in $0.01 \mathrm{M}$ phosphate buffer, CPT and 2-Cl-IB-MECA were dissolved in 1\% DMSO, and MSX-3 hydrate was dissolved in water. All solutions were sterilized by $0.2 \mu \mathrm{m}$ filtration before use except for pentobarbital sodium, which was obtained as an injectable solution $(50 \mathrm{mg} / \mathrm{ml})$ (Abbott Laboratories).

\section{Results}

Onset of torpor requires $A_{1} A R$ activation

To investigate whether $A_{1} A R$ activation by endogenous adenosine within the CNS is necessary for the onset of spontaneous torpor in AGS, the $\mathrm{A}_{1} \mathrm{AR}$ antagonist CPT $(3 \mathrm{nmol} / 10 \mu \mathrm{l})$ was administered into the lateral ventricle during onset of spontaneous torpor, via an indwelling intracerebroventricular cannula. $\mathrm{CPT}$, delivered by an investigator unaware of treatment, reversed torpor onset in all animals tested, while vehicle had no effect (Fig. 1).

\section{Sensitivity to the torpor-inducing effects of the $A_{1} A R$ agonist} CHA increases as the hibernation season progresses

We next asked whether $A_{1} A R$ activation within the CNS was sufficient to induce a state of torpor that mimicked spontaneous torpor both in temporal profile and in magnitude of decline in the rate of $\mathrm{O}_{2}$ consumption and $T_{\mathrm{b}}$. We also investigated whether the sensitivity to torpor-inducing effects of $\mathrm{CHA}$, an $\mathrm{A}_{1} \mathrm{AR}$ ago-

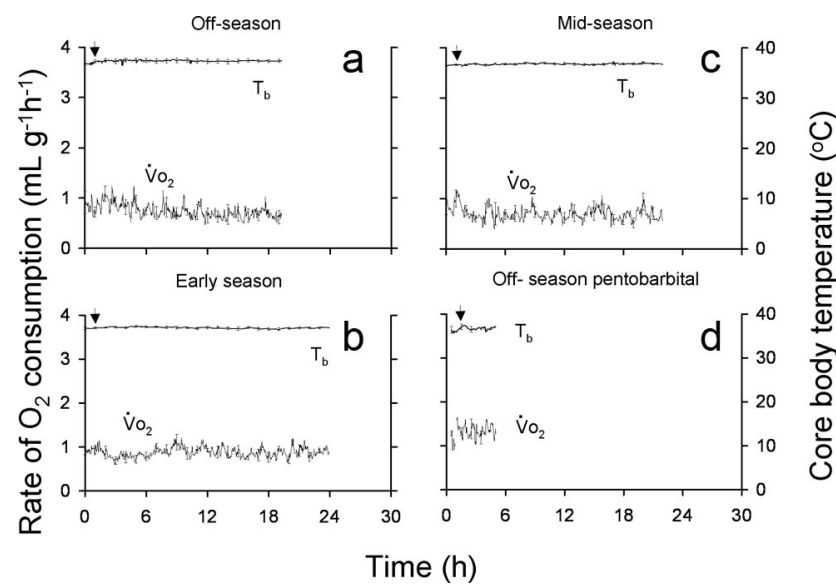

Figure 3. None of the vehicles tested produced a notable effect on $T_{b}$ or $\dot{V}_{0 .} \cdot \boldsymbol{a}-\boldsymbol{d}$, Vehicle (0.01 м phosphate buffer, i.c.v., for $\mathrm{CHA}$; $\boldsymbol{a}-\boldsymbol{c}$ ); and saline (i.p., for pentobarbital; $\boldsymbol{d}$ ) failed to produce any notable change in $T_{\mathrm{b}}$ or $\dot{V}_{0}$. Data shown are means and SEM; $n=6 \mathrm{AGSS}$.

nist, would increase as the hibernation season progressed. Six AGSs instrumented with intracerebroventricular cannula open to the lateral ventricle were administered CHA $(0.5 \mathrm{nmol} / 10 \mu \mathrm{l})$ or vehicle in a blinded, balanced, cross-over fashion at three times of the year. These three tests commenced during the off-season when AGSs were not displaying spontaneous torpor, during the early hibernation season after all AGSs had begun to display spontaneous torpor, and during the middle of the hibernation season.

CHA administered during the off-season, induced a slight, temporary, reduction in $\mathrm{O}_{2}$ consumption and $T_{\mathrm{b}}$ in all AGSs tested (Fig. $2 a, g$ ). Early in the hibernation season the same dose of 
Table 1. Characteristics of AGS treated with CHA $(0.5 \mathrm{nmol}$, i.c.v) during the three test seasons

\begin{tabular}{|c|c|c|c|c|c|c|}
\hline & $05-25$ & $04-86$ & 04-58 & $05-03$ & 05-13 & $05-06$ \\
\hline Age & Adult & Adult & Adult & Adult & Adult & Adult \\
\hline Sex & Male & Male & Male & Male & Male & Male \\
\hline Last day of torpor during previous season & 18-Apr-07 & 4-Feb-07 & 19-Feb-07 & 3-Feb-07 & 17-Jan-07 & 15-May-07 \\
\hline First day of spontaneous torpor & 26-Aug-07 & 1-Jul-07 & 25-Jul-07 & 22-Jul-07 & 1-Jul-07 & 1-Jul-07 \\
\hline \multicolumn{7}{|l|}{ Body weight $(\mathrm{g})$} \\
\hline Off-season & 601 & 551 & 820 & 680 & 630 & 681 \\
\hline Early season & 860 & 881 & 801 & 940 & 700 & 801 \\
\hline Midseason & 906 & 800 & 860 & 808 & 700 & 751 \\
\hline \multicolumn{7}{|c|}{ No. of spontaneous torpor bouts prior to CHA test } \\
\hline Off-season & 0 & 0 & 0 & 0 & 0 & 0 \\
\hline Early season & 3 & 5 & 4 & 4 & 8 & 7 \\
\hline Midseason & 9 & 9 & 8 & 9 & 13 & 13 \\
\hline \multicolumn{7}{|l|}{ Minimum $T_{\mathrm{b}}$ induced by $\mathrm{CHA}\left({ }^{\circ} \mathrm{C}\right)$} \\
\hline Early season & 31.9 & 32.0 & 32.8 & 30.9 & 4.3 & 3.9 \\
\hline Midseason & 4.6 & 3.9 & 5.2 & 5.3 & 4.3 & 4.7 \\
\hline \multicolumn{7}{|c|}{ Minimum $\dot{V}_{0_{2}}$ induced by $\mathrm{CHA}\left(\mathrm{ml} \cdot \mathrm{g}^{-1} \cdot \mathrm{h}^{-1}\right)$} \\
\hline Early season & 0.22 & 0.17 & 0.26 & 0.3 & $<0.02$ & $<0.02$ \\
\hline Midseason & $<0.02$ & $<0.02$ & $<0.02$ & $<0.02$ & $<0.02$ & $<0.02$ \\
\hline
\end{tabular}

Column heads are AGS ID numbers.

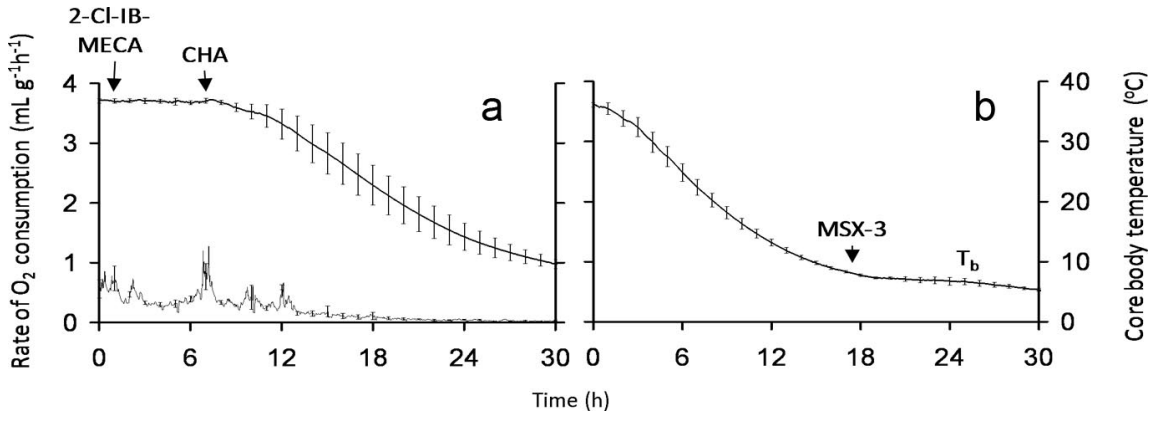

Figure 4. CHA-induced and spontaneous torpor is specific to $A_{1} A R$. $\boldsymbol{a}$, The selective $A_{3} A R$ agonist 2-Cl-IB-MECA ( 3 nmol, i.c.v.) failed to induce torpor in any of the animals tested, while a subsequent injection of $\mathrm{CHA}(0.5 \mathrm{nmol}$, i.c.v.) induced torpor $(n=3)$. Top trace is $T_{\mathrm{b}}$; bottom trace is $\dot{V}_{0} . \boldsymbol{b}$, MSX-3 (3 nmol, i.c.V.), a water-soluble prodrug of the $\mathrm{A}_{2} \mathrm{AR}$ antagonist MSX-2, failed to reverse onset of spontaneous torpor $(n=3)$. Data shown are means and SEM.

CHA delivered to the same six AGSs induced a torpor-like decline in $\mathrm{O}_{2}$ consumption and $T_{\mathrm{b}}$ in two of six animals tested (Fig. $2 b, h$ ) and an off-season-like response in the remaining four animals (Fig. 2c,i). By mid-hibernation season (midseason), the same dose of CHA induced a torpor-like response in all of these same six animals (Fig. $2 d, j$ ). The torpor-like response to CHA resembled spontaneous entry into torpor (Fig. $2 e, k$ ). Pentobarbital (20 mg/kg, i.p.) produced an off-season-like response regardless of season (Fig. 2f,l). Vehicle (phosphate buffer, i.c.v. for CHA or saline, i.p. for pentobarbital) did not produce a notable effect on $T_{\mathrm{b}}$ or rate of $\mathrm{O}_{2}$ consumption at any season tested (Fig. 3).

We asked whether characteristics such as body weight, sex, age, and timing or evidence of prior torpor bouts predicted the magnitude or quality of the CHA-induced response during the early hibernation season. The two animals that displayed CHAinduced torpor when tested early in the season (Early season) had exhibited slightly more bouts of spontaneous torpor before this CHA test than the other four animals (Table 1). Other variables did not predict the larger response to CHA in these animals. Data shown in Table 1 illustrate that the hibernation season was defined by the presence of spontaneous torpor. In these animals, progression of the hibernation season was evident from the number of torpor bouts noted since the onset of spontaneous torpor. The circannual cycle of obligate hibernators, such as AGS, will free run when animals are housed under constant L:D conditions
(Pengelley et al., 1976; Lee and Zucker, 1991). This free-running circannual cycle explains why the first day of spontaneous torpor occurred in July in many of the animals in this study.

\section{CHA-induced and spontaneous torpor is specific to $A_{1} A R$}

Although CHA is fairly selective for $\mathrm{A}_{1} \mathrm{AR}$, it has some affinity for $\mathrm{A}_{3} \mathrm{AR}$ (Gao et al., 2003), leading us to ask whether $A_{3} A R$ activation could account for CHA-induced torpor. The $\mathrm{A}_{3} \mathrm{AR}$ agonist 2-Cl-IB-MECA (3 nmol/10 $\mu$ l, i.c.v.), delivered during midseason, failed to induce torpor in any of the animals tested, although a subsequent injection of CHA $(0.5 \mathrm{nmol} / 10 \mu \mathrm{l}$, i.c.v.) induced torpor as observed previously (Fig. 4a), indicating that $\mathrm{A}_{3} \mathrm{AR}$ activation is not sufficient to induce torpor. Both $A_{1} A R$ and $A_{2 a} A R$ play a role in sleep (Porkka-Heiskanen et al., 1997; Huang et al., 2005; Oishi et al., 2008); and torpor is in part an extension of sleep (Walker et al., 1977). We therefore asked whether $\mathrm{A}_{2 \mathrm{a}} \mathrm{AR}$ receptors contribute to the onset of torpor. MSX-3, a water-soluble prodrug of the selective, high-affinity $\mathrm{A}_{2 \mathrm{a}} \mathrm{AR}$ antagonist MSX-2 (Solinas et al., 2005), failed to reverse onset of spontaneous torpor in any of the animals tested (Fig. 4b). These results indicate that $\mathrm{A}_{2 \mathrm{a}} \mathrm{AR}$ activation is not necessary for torpor onset.

Pentobarbital is a positive allosteric modulator of $\mathrm{GABA}_{\mathrm{A}}$ receptors, promotes sleep, and shows seasonal-dependent changes in efficacy across the hibernation season in thirteen-lined ground squirrels (Hengen et al., 2011). To investigate whether the seasonal change in response to CHA-induced torpor was specific to an adenosine agonist, pentobarbital was administered during the midseason and off-season. Pentobarbital was administered, intraperitoneally, to two groups of animals. One group was tested during the off-season, when animals failed to demonstrate spontaneous torpor. Another group was tested during the mid-hibernation season, when the total number of bouts of spontaneous torpor ranged between 12 and 16 bouts. Figure 2, $f$ and $l$, shows that pentobarbital failed to induce torpor at any 
Table 2. Characteristics of AGSs treated with pentobarbital $(20 \mathrm{mg} / \mathrm{kg}$, i.p.) during the off-season and during the middle of the hibernation season

\begin{tabular}{|c|c|c|c|c|c|c|}
\hline & \multicolumn{3}{|c|}{ Off-season } & \multicolumn{3}{|c|}{ Midseason } \\
\hline & $04-25$ & $04-48$ & $04-73$ & $08-61$ & $08-46$ & $07-74$ \\
\hline Age & Adult & Adult & Adult & Adult & Adult & Adult \\
\hline Sex & Male & Male & Male & Female & Female & Male \\
\hline Body weight (g) & 714 & 707 & 689 & 826 & 606 & 911 \\
\hline $\begin{array}{l}\text { No. of spontaneous torpor bouts prior } \\
\text { to pentobarbital test }\end{array}$ & 0 & 0 & 0 & 12 & 16 & 13 \\
\hline $\begin{array}{l}\text { Minimum } T_{\mathrm{b}} \text { induced by pentobarbital } \\
\left({ }^{\circ} \mathrm{C}\right)\end{array}$ & 30.0 & 32.6 & 32.0 & 33.2 & 30.0 & 33.1 \\
\hline $\begin{array}{l}\text { Minimum } V_{\mathrm{O}_{2}} \text { induced by pentobarbital } \\
\qquad\left(\mathrm{ml} \cdot \mathrm{g}^{-1} \cdot \mathrm{h}^{-1}\right)\end{array}$ & 0.56 & 0.85 & 0.52 & 0.62 & 0.23 & 0.52 \\
\hline
\end{tabular}

Table 3. Characteristics of AGSs treated with CHA ( $0.5 \mathrm{mg} / \mathrm{kg}$, i.p.)

\begin{tabular}{|c|c|c|c|c|c|c|c|c|c|}
\hline & \multicolumn{5}{|c|}{ Off-season } & \multicolumn{4}{|c|}{ Midseason } \\
\hline & $05-27$ & $07-106$ & $05-21$ & $07-54$ & $07-98$ & $08-82$ & $08-98$ & $08-86$ & $08-77$ \\
\hline Age & Adult & Adult & Adult & Adult & Adult & Adult & Adult & Adult & Adult \\
\hline Sex & Male & Male & Male & Male & Male & Female & Female & Female & Female \\
\hline Body weight (g) & 929 & 769 & 722 & 951 & 684 & 713 & 711 & 700 & 722 \\
\hline $\begin{array}{l}\text { No. of spontaneous } \\
\text { torpor bouts prior } \\
\text { to } \mathrm{CHA}\end{array}$ & 0 & 0 & 0 & 0 & 0 & 9 & 7 & 7 & 8 \\
\hline $\begin{array}{c}\text { Minimum } T_{\mathrm{b}} \text { induced } \\
\text { by } \mathrm{CHA}\left({ }^{\circ} \mathrm{C}\right)\end{array}$ & 30.8 & 35.2 & 35.9 & 34.6 & 32.7 & 3.8 & 4.4 & 5.1 & 4.4 \\
\hline
\end{tabular}

season tested. Table 2 shows that the characteristics of AGSs treated with pentobarbital during these two seasons are similar to the off-season and midseason groups of AGSs treated with CHA. Injections of pentobarbital, i.p., were noted to produce a brief, but detectible, increase in $\dot{V}_{\mathrm{O}_{2}}$ that was not noted with intracerebroventricular administration of CHA (Fig. $2 f$ ). To ensure that intraperitoneal injections did not interfere with drug-induced torpor, separate groups of AGSs were treated with CHA (0.5 $\mathrm{mg} / \mathrm{kg}$, i.p.) during the off-season and during the midseason. Data shown in Table 3 show that intraperitoneal injections of CHA induced torpor during the midseason, but not during the off-season as seen for intracerebroventricular administration. Characteristics of AGSs were similar to other groups of animals tested during these two seasons.

\section{Discussion}

These results indicate that the CNS regulates the onset of torpor via activation of $A_{1} A R$. Sensitivity to the torpor-inducing effects of the $\mathrm{A}_{1} \mathrm{AR}$ agonist $\mathrm{CHA}$ increases as the hibernation season progresses, and the torpor-inducing efficacy of $\mathrm{CHA}$ is specific to $\mathrm{A}_{1} \mathrm{AR}$ activation. It is unlikely that the seasonal response to $\mathrm{CHA}$ was due to differences in cold adaptation, since animals were housed at $2^{\circ} \mathrm{C}$ throughout the study period.

Torpor in hibernating animals represents an extreme example of decreased metabolism, but the central or peripheral sites or signaling mechanisms involved in torpor onset have been unknown (Heldmaier et al., 2004). By administering purinergic ligands specific for the adenosine $\mathrm{A}_{1}, \mathrm{~A}_{2 \mathrm{a}}$, or $\mathrm{A}_{3}$ receptors (Table 4) into the lateral ventricle of AGSs at various times across the annual hibernation cycle, we find that adenosine within the CNS meets all of the necessary requirements for an endogenous mediator of torpor in AGS. A progressive increase in the sensitivity of AGS to $A_{1}$ AR-mediated signaling within the CNS parallels the seasonal transition into the hibernation phenotype and provides
Table 4. Binding affinities for adenosine ligands

\begin{tabular}{llcccc}
\hline & \multicolumn{5}{l}{$K_{\mathrm{i}}(\mathrm{nM})$} \\
\cline { 2 - 6 } Drug & Dose (nmol) & $\mathrm{A}_{1} \mathrm{AR}$ & $\mathrm{A}_{2 \mathrm{a}} \mathrm{AR}$ & $\mathrm{A}_{2 \mathrm{~b}} \mathrm{AR}$ & $\mathrm{A}_{3} \mathrm{AR}$ \\
\hline CPT & 3.0 & $10.9^{a}$ & $3170^{b}$ & $902_{\mathrm{h}}{ }^{b}$ & $>10,000^{b}$ \\
MSX-2 & 3.0 & $900^{c}$ & $9.1^{b}$ & $2,900_{\mathrm{h}}^{b}$ & $>10,000^{b}$ \\
CHA & 0.5 & $0.9^{d}$ & $514^{e}$ & n.a. & $167^{e}$ \\
2-Cl-IB-MECA & 3.0 & $820^{f}$ & $470^{f}$ & n.a. & $0.33^{f}$
\end{tabular}

${ }^{a}$ Bruns et al. (1986); ${ }^{b}$ Solinas et al. (2005); 'Sauer et al. (2000); ${ }^{d}$ Gao et al. (2003); ${ }^{e}$ van Galen et al. (1994); ${ }^{\prime}$ Kim et al. (1994); h, human recombinant receptors; n.a., not available.

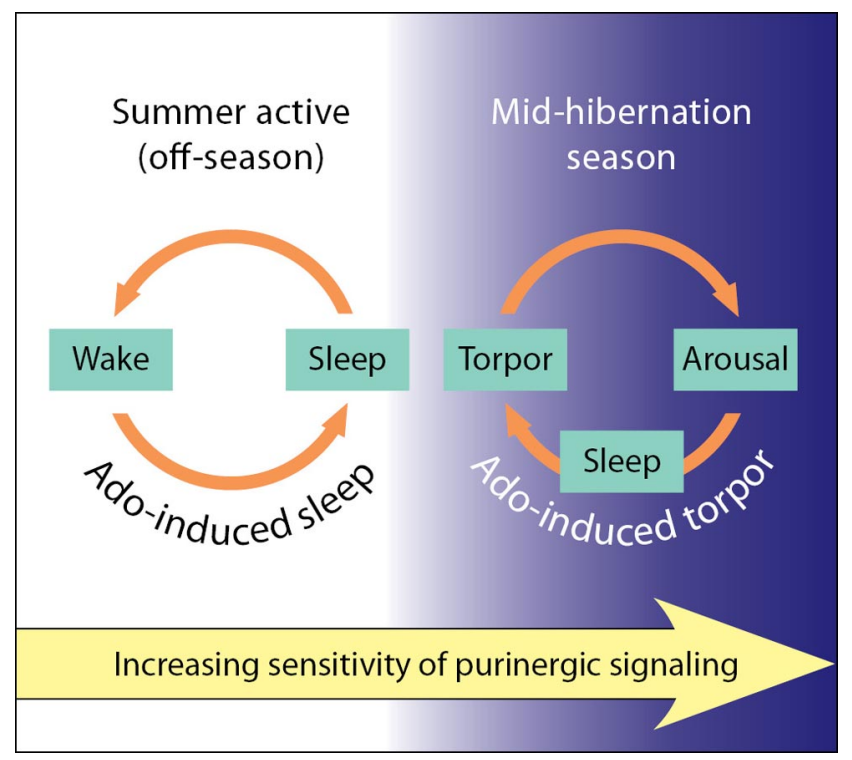

Figure 5. Enhanced purinergic signaling turns on the seasonal switch to hibernate in arctic ground squirrels. Schematic diagram modified from the two-switch model of Serkova et al. (2007) illustrates how seasonal sensitization of purinergic signaling primes the brain for adenosine-induced torpor during the hibernation season. The off-season, commonly referred to as the "summer-active" season, is indicated by a white background. During the off-season, overflow of adenosine that occurs as part of normal purinergic signaling fails to induce torpor. Here we use homeostatic sleep drive as an example of normal purinergic signaling (PorkkaHeiskanen et al., 1997; Basheer et al., 2004). The present report shows that an increase in the gain in purinergic signaling occurs during the hibernation season. The hibernation season is indicated by a dark background and the shading from light to dark illustrates an increase in gain in purinergic signaling as the season progresses. This increased gain in purinergic signaling during the hibernation season primes the brain such that overflow of endogenous adenosine with subsequent activation of $A_{1} A R$ now induces torpor. The effect of endogenous adenosine is demonstrated by the ability of an $A_{1} A R$ antagonist (CPT) to reverse onset of spontaneous torpor.

an example of a seasonal switch proposed in the two-switch model for obligate hibernation (Serkova et al., 2007). We show that in the context of this model, increased gain in central purinergic signaling serves as the first switch, and stimulation of central $A_{1} A R$ by endogenous adenosine serves as a second switch, that induces torpor (Fig. 5).

Because $A_{1} A R$ activation is necessary for the homeostatic sleep response (Bjorness et al., 2009), an increased gain in purinergic signaling predicts an increase in sleep drive during the hibernation season. Although sleep drive has not been monitored in AGS, golden-mantled ground squirrels sleep more during the hibernation season (Walker et al., 1980).

Prolonged torpor in hibernating mammals is distinguished by at least three distinct processes that include onset of torpor, maintenance of torpor, and arousal from torpor (Drew et al., 2007). In hamsters (M. auratus), $A_{1} A R$ activation is necessary for torpor onset, as shown here for AGS, but is not necessary to maintain prolonged torpor (Tamura et al., 2005). Seasonal alter- 
ations in signaling events involved in torpor maintenance or interbout arousal are as yet unclear. Moreover, while the present results demonstrate that $A_{1} A R$ activation is necessary and sufficient to induce torpor in AGS, it is unlikely that adenosine is the only neuromodulator involved with torpor onset.

The present results clearly show that $\mathrm{A}_{1} \mathrm{AR}$ stimulation is sufficient to initiate torpor onset that results in a decrease in metabolic rate to levels that are below basal metabolic rate, a value determined to be within 0.40 and $0.61 \mathrm{ml} \cdot \mathrm{g}^{-1} \cdot \mathrm{h}^{-1}$ for AGS (Scholander et al., 1950; Withers et al., 1979). Geiser (2004) describes a scenario in which decreased thermogenesis leads to cooling, which then via thermodynamic effects decreases oxygen consumption to torpid metabolic rates. This scenario may account for how central $A_{1} A R$-induced inhibition of thermogenesis in AGS could lead to a consequent lowering of $T_{\mathrm{b}}$ that is then sufficient to account for torpid metabolic rates reported here. This explanation incorporates two of three proposed mechanisms of metabolic suppression in hibernating animals. One mechanism includes the central inhibition of thermogenesis associated with a lowering of brain temperature necessary to induce thermogenesis (Heller et al., 1977). A second mechanism involves thermodynamic effects of cooling on metabolic rate described by the Van't Hoff equation (Atkins and De Paula, 2006). In biological systems, temperature effects are often referred to as $\mathrm{Q}_{10}$ effects, where reaction rates generally double or triple with every $10^{\circ} \mathrm{C}$ increase in temperature (Schmidt-Nielsen, 1997). A third set of mechanisms involves "active" suppression of cellular processes such as ion channel arrest (Hochachka, 1986) or inhibition of cellular respiration (Muleme et al., 2006). It is difficult to explain how central $\mathrm{A}_{1} \mathrm{AR}$ activation could directly cause global, "active" suppression of cellular processes; however, global effects could occur downstream to torpor initiation.

Given that cooling contributes to metabolic rate reduction, cooling during onset of torpor will influence the subsequent decrease in metabolic rate. Unexpectedly, a rapid rate of cooling induced by CHA during the off-season contrasted with a significantly slower rate of cooling induced by CHA during the hibernation season. All animals had been housed at $2^{\circ} \mathrm{C}$ for several months, so cold adaptation is unlikely to account for differences in the rate of cooling. $\mathrm{O}_{2}$ consumption and $T_{\mathrm{b}}$ were measured in the present study as physiological parameters used to clearly distinguish torpor onset from hypothermia. Since thermoregulatory systems are independently regulated, further study of multiple thermoeffector activities is warranted to achieve a more complete understanding of torpor as a thermoregulatory response (Romanovsky, 2007; Nakamura et al., 2009).

The mechanism that increases the gain in purinergic signaling may involve changes in receptor expression or function, changes in extracellular levels of adenosine, or changes in neural circuits regulating sleep, metabolism, or body temperature. Seasonal changes in sensitivity to allosteric modulation of $\mathrm{GABA}_{\mathrm{A}}$ receptors by pentobarbital in thirteen-lined ground squirrels have been observed. These changes are restricted to cardiorespiratory neurons and are associated with altered expression of $\varepsilon$ and $\delta$ $\mathrm{GABA}_{\mathrm{A}}$ receptor subunits (Hengen et al., 2009, 2011). In the present study, pentobarbital did not induce torpor; however, a role for altered allosteric modulation of $\mathrm{GABA}_{\mathrm{A}} \mathrm{R}$ in adenosinemediated torpor induction cannot be ruled out.

The capacity of an $\mathrm{A}_{1} \mathrm{AR}$ agonist to induce a torpid state may confer some of the neuroprotective aspects of hibernation noted previously (Zhou et al., 2001). Central $A_{1} A R$ stimulation prevents cardiac arrhythmias during cooling in hamsters (Miyazawa et al., 2008) and may offer a means to avoid cardiac arrhythmias or other side effects encountered during therapeutic hypothermia (Polderman and Herold, 2009). $\mathrm{H}_{2} \mathrm{~S}$-induced suspended animation has led to investigation of $\mathrm{H}_{2} \mathrm{~S}$ as a therapeutic agent (Blackstone et al., 2005). Likewise, understanding how hibernating mammals regulate metabolic suppression has potential to translate to improved therapies for conditions in which oxygen and energy supply fail to meet demand. Such conditions include stroke, cardiac arrest, hemorrhagic shock, and trauma.

\section{References}

Atkins PW, De Paula J (2006) Atkins' physical chemistry, Ed 8. New York: W.H. Freeman.

Barnes BM (1989) Freeze avoidance in a mammal: body temperatures below 0 degree $C$ in an arctic hibernator. Science 244:1593-1595.

Barros RC, Branco LG, Cárnio EC (2006) Respiratory and body temperature modulation by adenosine A1 receptors in the anteroventral preoptic region during normoxia and hypoxia. Respir Physiol Neurobiol 153:115-125.

Basheer R, Strecker RE, Thakkar MM, McCarley RW (2004) Adenosine and sleep-wake regulation. Prog Neurobiol 73:379-396.

Benington JH, Kodali SK, Heller HC (1995) Stimulation of A1 adenosine receptors mimics the electroencephalographic effects of sleep deprivation. Brain Res 692:79-85.

Bjorness TE, Kelly CL, Gao T, Poffenberger V, Greene RW (2009) Control and function of the homeostatic sleep response by adenosine A1 receptors. J Neurosci 29:1267-1276.

Blackstone E, Morrison M, Roth MB (2005) H2S induces a suspended animation-like state in mice. Science 308:518.

Bruns RF, Lu GH, Pugsley TA (1986) Characterization of the A2 adenosine receptor labeled by $[3 \mathrm{H}] \mathrm{NECA}$ in rat striatal membranes. Mol Pharmacol 29:331-346.

Carey HV, Andrews MT, Martin SL (2003) Mammalian hibernation: cellular and molecular responses to depressed metabolism and low temperature. Physiol Rev 83:1153-1181.

Dausmann KH, Glos J, Ganzhorn JU, Heldmaier G (2004) Physiology: hibernation in a tropical primate. Nature 429:825-826.

Drew KL, Buck CL, Barnes BM, Christian SL, Rasley BT, Harris MB (2007) Central nervous system regulation of mammalian hibernation: implications for metabolic suppression and ischemia tolerance. J Neurochem 102:1713-1726.

Gao ZG, Blaustein JB, Gross AS, Melman N, Jacobson KA (2003) N6substituted adenosine derivatives: selectivity, efficacy, and species differences at A3 adenosine receptors. Biochem Pharmacol 65:1675-1684.

Geiser F (2004) Metabolic rate and body temperature reduction during hibernation and daily torpor. Annu Rev Physiol 66:239-274.

Heldmaier G, Ortmann S, Elvert R (2004) Natural hypometabolism during hibernation and daily torpor in mammals. Respir Physiol Neurobiol 141:317-329.

Heller HC, Poulson TL (1970) Circadian rhythms-II. Endogenous and exogenous factors controlling reproduction and hibernation in chipmunks (Eutamias) and ground squirrels (Spermophilus). Comp Biochem Physiol 33:357-383

Heller HC, Colliver GW, Beard J (1977) Thermoregulation during entrance into hibernation. Pflügers Arch 369:55-59.

Hengen KB, Behan M, Carey HV, Jones MV, Johnson SM (2009) Hibernation induces pentobarbital insensitivity in medulla but not cortex. Am J Physiol Regul Integr Comp Physiol 297:R1028-R1036.

Hengen KB, Gomez TM, Stang KM, Johnson SM, Behan M (2011) Changes in ventral respiratory column GABAaR \{varepsilon\}- and $\{$ delta\}-subunits during hibernation mediate resistance to depression by EtOH and pentobarbital. Am J Physiol Regul Integr Comp Physiol 300:R272-R283.

Hochachka PW (1986) Defense strategies against hypoxia and hypothermia. Science 231:234-241.

Huang ZL, Qu WM, Eguchi N, Chen JF, Schwarzschild MA, Fredholm BB, Urade Y, Hayaishi O (2005) Adenosine A2A, but not A1, receptors mediate the arousal effect of caffeine. Nat Neurosci 8:858-859.

Karpovich SA, Tøien Ø, Buck CL, Barnes BM (2009) Energetics of arousal episodes in hibernating arctic ground squirrels. J Comp Physiol B 179:691-700.

Kim HO, Ji XD, Siddiqi SM, Olah ME, Stiles GL, Jacobson KA (1994) 
2-Substitution of N6-benzyladenosine-5' -uronamides enhances selectivity for A3 adenosine receptors. J Med Chem 37:3614-3621.

Klotz KN (2000) Adenosine receptors and their ligands. Naunyn Schmiedebergs Arch Pharmacol 362:382-391.

Lee TM, Zucker I (1991) Suprachiasmatic nucleus and photic entrainment of circannual rhythms in ground squirrels. J Biol Rhythms 6:315-330.

Miller LP, Hsu C (1992) Therapeutic potential for adenosine receptor activation in ischemic brain injury. J Neurotrauma 9 [Suppl 2]: S563-S577.

Miyazawa S, Shimizu Y, Shiina T, Hirayama H, Morita H, Takewaki T (2008) Central A1-receptor activation associated with onset of torpor protects the heart against low temperature in the Syrian hamster. Am J Physiol Regul Integr Comp Physiol 295:R991-R996.

Muleme HM, Walpole AC, Staples JF (2006) Mitochondrial metabolism in hibernation: metabolic suppression, temperature effects, and substrate preferences. Physiol Biochem Zool 79:474-483.

Nakamura Y, Nakamura K, Morrison SF (2009) Different populations of prostaglandin EP3 receptor-expressing preoptic neurons project to two fever-mediating sympathoexcitatory brain regions. Neuroscience 161:614-620.

Oishi Y, Huang ZL, Fredholm BB, Urade Y, Hayaishi O (2008) Adenosine in the tuberomammillary nucleus inhibits the histaminergic system via A1 receptors and promotes non-rapid eye movement sleep. Proc Natl Acad Sci U S A 105:19992-19997.

Pengelley ET, Asmundson SJ, Barnes B, Aloia RC (1976) Relationship of light intensity and photoperiod to circannual rhythmicity in the hibernating ground squirrel, Citellus lateralis. Comp Biochem Physiol A 53:273-277.

Polderman KH, Herold I (2009) Therapeutic hypothermia and controlled normothermia in the intensive care unit: practical considerations, side effects, and cooling methods. Crit Care Med 37:1101-1120.

Porkka-Heiskanen T, Kalinchuk AV (2011) Adenosine, energy metabolism and sleep homeostasis. Sleep Med Rev 15:123-135.

Porkka-Heiskanen T, Strecker RE, Thakkar M, Bjørkum AA, Greene RW, McCarley RW (1997) Adenosine: a mediator of the sleep-inducing effects of prolonged wakefulness. Science 276:1265-1268.

Romanovsky AA (2007) Thermoregulation: some concepts have changed. Functional architecture of the thermoregulatory system. Am J Physiol Regul Integr Comp Physiol 292:R37-R46.

Sauer R, Maurinsh J, Reith U, Fülle F, Klotz KN, Müller CE (2000) Water- soluble phosphate prodrugs of 1-propargyl-8-styrylxanthine derivatives, A(2A)-selective adenosine receptor antagonists. J Med Chem 43:440-448.

Schmidt-Nielsen K (1997) Animal physiology: adaptation and environment, Ed 5. Cambridge: Cambridge UP.

Scholander PF, Hock R, Walters V, Irving L (1950) Adaptation to cold in arctic and tropical mammals and birds in relation to body temperature, insulation, and basal metabolic rate. Biol Bull 99:259-271.

Serkova NJ, Rose JC, Epperson LE, Carey HV, Martin SL (2007) Quantitative analysis of liver metabolites in three stages of the circannual hibernation cycle in 13-lined ground squirrels by NMR. Physiol Genomics 31:15-24.

Shiomi H, Tamura Y (2000) Pharmacological aspects of mammalian hibernation: central thermoregulation factors in hibernation cycle. Nippon Yakurigaku Zasshi 116:304-312.

Solinas M, Ferré S, Antoniou K, Quarta D, Justinova Z, Hockemeyer J, Pappas LA, Segal PN, Wertheim C, Müller CE, Goldberg SR (2005) Involvement of adenosine $\mathrm{A} 1$ receptors in the discriminative-stimulus effects of caffeine in rats. Psychopharmacology (Berl) 179:576-586.

Tamura Y, Shintani M, Nakamura A, Monden M, Shiomi H (2005) Phasespecific central regulatory systems of hibernation in Syrian hamsters. Brain Res 1045:88-96.

van Galen PJ, van Bergen AH, Gallo-Rodriguez C, Melman N, Olah ME, IJzerman AP, Stiles GL, Jacobson KA (1994) A binding site model and structure-activity relationships for the rat $\mathrm{A} 3$ adenosine receptor. $\mathrm{Mol}$ Pharmacol 45:1101-1111.

Wagner JA, Horvath SM, Dahms TE, Reed S (1973) Validation of opencircuit method for the determination of oxygen consumption. J Appl Physiol 34:859-863.

Walker JM, Glotzbach SF, Berger RJ, Heller HC (1977) Sleep and hibernation in ground squirrels (Citellus spp): electrophysiological observations. Am J Physiol 233:R213-R221.

Walker JM, Haskell EH, Berger RJ, Heller CH (1980) Hibernation and circannual rhythms of sleep. Physiol Zool 53:8-11.

Withers PC, Casey TM, Casey KK (1979) Allometry of respiratory and haematological parameters of arctic mammals. J Comp Physiol Behav 64:343-350.

Zhou F, Zhu X, Castellani RJ, Stimmelmayr R, Perry G, Smith MA, Drew KL (2001) Hibernation, a model of neuroprotection. Am J Pathol 158:21452151. 